Research Paper

\title{
Wnt Signaling as a Possible Promoting Factor of Cell Differentiation in Pleomorphic Adenomas
}

\author{
Yukiko Okuda1,3, Keisuke Nakano1,4凶 , Koji Suzuki², Yoshihiko Sugita2,5, Katsutoshi Kubo ${ }^{2,5}$, Hatsuhiko \\ Maeda 2,5 , Norimasa Okafuji 6 , Hiromasa Hasegawa1,4 and Toshiyuki Kawakami1 \\ 1. Hard Tissue Pathology Unit, Matsumoto Dental University Graduate School of Oral Medicine, Shiojiri, Japan \\ 2. Department of Oral Pathology, School of Dentistry, Aichi Gakuin University, Nagoya, Japan \\ 3. Department of Oral and Maxillofacial Surgery, Hyogo Prefectural Tsukaguchi Hospital, Amagasaki, Japan \\ 4. Department of Oral Pathology, Matsumoto Dental University School of Dentistry, Shiojiri, Japan \\ 5. Center for Advanced Oral Science, Aichi Gakuin University, Nagoya, Japan \\ 6. Clinical Evaluation Unit, Matsumoto Dental University Graduate School of Oral Medicine, Shiojiri, Japan
}

$\square$ Corresponding author: Dr. Keisuke Nakano, DDS, PhD, Associate Professor, Hard Tissue Pathology Unit, Matsumoto Dental University Graduate School of Oral Medicine, Shiojiri, 399-0781 Japan; Phone +81-263-51-2035; Fax +81-263-51-2035; E-mail keisuke1@po.mdu.ac.jp

() Ivyspring International Publisher. This is an open-access article distributed under the terms of the Creative Commons License (http://creativecommons.org/ licenses/by-nc-nd/3.0/). Reproduction is permitted for personal, noncommercial use, provided that the article is in whole, unmodified, and properly cited.

Received: 2014.04.20; Accepted: 2014.06.25; Published: 2014.07.10

\begin{abstract}
There are well known that $\mathrm{Wnt}$ signaling was some roles of cell differentiation at the development tissues, especially the oral and maxillofacial regions of some developmental stages. Therefore, to determine Wnt signaling in the pleomorphic adenoma tissues, we examined. The expression of $\mathrm{Wntl}$ and $\beta$-catenin as well as the distribution of various cytoskeletal proteins CK7 and CK I 3 was examined in 30 cases of pleomorphic adenoma by immunohistochemistry. Wntl was detected in almost all tumor cells. The peripheral columnar cells in squamous metaplasia and small cuboidal cells in duct-like structures were strongly positive to $\mathrm{Wntl}$. Although $\beta$-catenin was clearly localized on the cell membrane of tumor cells, nuclear translocation was observed in small cuboidal cells and in some basaloid cells. The immunofluorescent staining pattern of $\mathrm{Wntl}$ and CK7 as well as $\mathrm{Wntl}$ and $\mathrm{CKI} 3$ was consistent with $\mathrm{IHC}$ results. Thus, in pleomorphic adenoma, Wnt is involved in tumor cell differentiation of peripheral columnar cells forming solid nests and small peripheral columnar cells forming duct-like structures. Moreover, among the three currently known Wnt pathways, $\beta$-catenin is the suggested pathway working during cell differentiation. Furthermore, peripheral columnar cells in solid tumor nests and in squamous metaplasia are governed by another Wnt pathway other than $\beta$-catenin. Therefore, $W n t$ signaling through $\beta$-catenin pathway may be involved in the 'mixed' differentiation characteristic of pleomorphic adenoma although another pathway may also be possibly working in other parts of the tumor tissue.
\end{abstract}

Key words: pleomorphic adenoma, Wnt signaling, $\beta$-catenin, cytokeratin, immunohistochemistry, cell differentiation

\section{Introduction}

Pleomorphic adenoma is the most frequently occurring benign epithelial tumor of the salivary gland (1). The neoplasm is histopathologically characterized by being diverse, consisting of polygonal epithelial cells forming ductal structures surrounded by myoepithelial cells. Typically, a transition from epithelial to mesenchymal component creates a third type of tumor stroma called cartilaginous or myxomatous tissue during the growth of the glandular structure. The myoepithelial cells are highly considered as neoplastic in origin. It is a general opinion that neoplastic myoepithelial cells are responsible for the formation of cartilaginous and myxomatous tissues $(2,3)$. However, the small cuboidal cells in tumor 
nests undergoing advanced differentiation, squamous epithelioid cells, plasmacytoid cells and other cells involved in mesenchymal transition have not been elucidated in previous researches. Consequently, the study focused on the differentiation of parenchymal tumor cells in pleomorphic adenoma.

It is currently known that Wnt signaling is implicated in cell proliferation and differentiation. Wnt is activated by the canonical $\beta$-catenin and non-canonical Wnt (PCP and $\mathrm{Ca}^{2+}$ ) pathways. In the $\beta$-catenin pathway, Wnt, secreted as a glycoprotein binds to receptors on the cell membrane, known to be involved in the suppression of differentiation and cellular response (4). Because Wnt signaling is also involved in the suppression and differentiation of cells, it was hypothesized that a pathway other than the canonical Wnt signaling via $\beta$-catenin might be involved in the 'mixed' differentiation characteristic of pleomorphic adenoma. Therefore, immunohistochemistry (IHC) was performed to include CK7 and CK13 based on the study of other literatures.

\section{Materials and Methods}

A total of 30 cases of pleomorphic adenoma from the archives of the Department of Oral Pathology, School of Dentistry, Aichi Gakuin University, were reassessed histopathologically based on WHO classification. The mean age is 51.5 years consisting of 13 male and 17 female. Fourteen were located in the palate, 5 were located in the parotid gland and 4 were located in the mandibular gland, and remaining 7 were in the other portions (Table 1). Samples were prepared for histopathological examination in a routine manner as follows. Specimens were fixed in neutral buffered formalin solution, dehydrated in series of alcohol, embedded in paraffin, serially sectioned into $4-\mu \mathrm{m}$ thickness and stained with hematoxylin and eosin (HE).

Table I. Cases examined

\begin{tabular}{|c|c|c|c|c|c|}
\hline \multicolumn{2}{|c|}{ Age } & \multicolumn{2}{|c|}{ Sex } & \multicolumn{2}{|c|}{ Location } \\
\hline \multirow[t]{6}{*}{ Average } & 51.5 & Male & 13 & Palate & 14 \\
\hline & & Female & 17 & Parotid gland & 5 \\
\hline & & & & Mandibular gland & 4 \\
\hline & & & & Upper lip & 3 \\
\hline & & & & Buccal mucosa & 3 \\
\hline & & & & Other & 1 \\
\hline
\end{tabular}

Specimens for IHC were deparaffinized followed by antigen retrieval in citric acid buffer, $\mathrm{pH} 6.0$ (Mitsubishi Chemical Mediene Co., Tokyo, Japan) at $120{ }^{\circ} \mathrm{C}$ for $15 \mathrm{~min}$. This was followed by blocking using Protein Block Serum-Free (Dako Japan Co., Tokyo,
Japan) at room temperature for $30 \mathrm{~min}$. Dako Chem Mate ENVISION kit/HRP was used for staining with rabbit polyclonal Wnt1 (Abcam, Cambridge, UK; $1 / 100$ ) and rabbit monoclonal $\beta$-catenin (E274, Abcam, Cambridge, UK; $1 / 500$ ) as primary antibodies. DAB was used to reveal antigenic sites.

For double immunofluorescence (IF), the previously described Wnt1 antibody, mouse monoclonal CK7 (Abcam, Cambridge, UK; 1/100) and mouse monoclonal CK13 (AE8, Abcam, Cambridge, UK; $1 / 100$ ) were used as primary antibodies. Double staining was carried out with Wnt1 and CK7 as well as Wnt1 and CK13 to confirm the localization in tumor tissues. Briefly, after deparaffinization, specimens were pre-treated in citrate buffer, $\mathrm{pH} 6.0$ (Mitsubishi Chemical Medience Co., Tokyo, Japan) in microwave for $1 \mathrm{~min}$ followed by blocking using Protein Block Serum-Free (Dako Japan Co., Ltd, Tokyo, Japan) at room temperature for $30 \mathrm{~min}$. For primary antibodies, Wnt1 and CK7 with 100 fold dilution each were prepared with Can Get Signal ${ }^{\circledR}$ (Toyobo Co., Osaka, Japan) and allowed to react for 16 hours at $4{ }^{\circ} \mathrm{C}$. For secondary antibody, Donkey anti-rabbit IgG H\&L (Alexa Fluor ${ }^{\circledR}$ 594, Abcam, Cambridge, UK; 1/200) and Donkey anti-mouse IgG H\&L (Alexa Fluor ${ }^{\circledR} 488$, Abcam, Cambridge, UK; 1/200) and Can Get Signal ${ }^{\circledR}$ (Tpyobo Co., Osaka, Japan) diluted in 200 fold were allowed to react at room temperature for $60 \mathrm{~min}$. Then after, the specimens were allowed to react with 1 $\mathrm{mg} / \mathrm{ml}$ DAPI for nuclear staining. Finally, the specimens were washed with TBS and mounted using Fluorescent Mounting Medium ${ }^{\circledR}$ (Dako Japan Co., Ltd, Tokyo, Japan).

The study was reviewed and approved by the Ethics Committee of Aichi Gakuin University (Number 284, approved on December 5, 2011) as part of the ‘Basic Clinicopathological Study and Method of Diagnosis Aimed to Understand the Pathogenesis and Development of Salivary Gland Tumor'.

\section{Results}

\section{Histopathological findings}

Microscopically, the tumor tissue consists of various copmponents. Within the tumor nests, duct-like structures are apparent. A double layer of basaloid cells and relatively large cuboidal cells formed the duct-like structures (Fig. 1-a). The neoplastic myoepithelial cells are scattered in the surrounding stroma creating the 'mixed' appearance of the tumor, which is a characteristic of pleomorphic adenoma (Fig. 1-b). Other parts of the stroma consist of so-called myxomatous tissue. Others consist of colorful substrates and glass-like substance creating an encapsulated cartilaginous stroma (Fig. 1-c). In the 
tumor cell nests, squamous-like tumor cells were formed (Fig. 1-d).

\section{Immunohistochemical findings}

Most tumor cells forming solid nests are positive to Wnt1. The expression was localized in the cytoplasm of small cuboidal cells in tumor nests and strong positive reaction was detected especially on cell membrane. In tumor cells that form duct-like structures, the cell membrane and cytoplasm of polygonal cells and of spindle-shaped cells in the outer layer of the duct-like structure showed positive reaction (Fig. 2-a). In addition, the cell membrane of spindle-shaped tumor cells, which proliferate in interstitial trabeculea is moderately positive while the scattered tumor cells showed strong positive reaction. In the typical mesenchymal component of pleomorphic adenoma, the neoplastic chondrocytes in glass-like structures are mostly negative. However, the spindle-shaped cells in myxomatous stroma showed positive reaction in the cytoplasm (Fig. 2-a).

Many of the squamous epithelioid cells in tumor nests exhibit positive reaction on the cell membrane. In the stroma showing squamous metaplasia, the basaloid cells strongly expressed Wnt1 although the same intensity was not observed in the keratinocytes (Fig. 2-b). In addition, positive reaction on the cell membrane of plasmacytoid cells in the tumor nests was detected.

With regard to $\beta$-catenin, the small cuboidal cells in the outermost layer of the duct-like structures in tumor nests showed strong positive reaction both in the cytoplasm and nucleus. The cytoplasm and nucleus of small cuboidal cells distributed in the outer part of the duct-like structures exhibited positive reaction (Fig. 2-c). Furthermore, the nuclei of the spindle-shaped cells in the mesenchymal component are positive but comparing to the tumor cells in duct-like structures, the nuclei were weakly positive. The neoplastic chondrocytes in glass-like stroma were almost negative. However, at the myxomatous stroma, few spindle cells showed positive cytoplasmic reaction.

Many squamous epithelioid tumor cells inside solid nests and plasmacytoid cells on the outside showed strong positive reaction. The basaloid cells in the mesenchymal component in particular showed strong positive reaction, but the keratinocytes exhibited weaker reaction (Fig. 2-d). The nuclei of the tumor cells with advanced growth showed strong positive reaction. In particular, the nuclei of small $\mathrm{cu}-$ boidal cells and polygonal cells in solid tumor nests showed positive reaction. The tumor cells making up the duct-like structures in solid nests were positive (Fig. 2-e) but the nuclei of the cells showing squamous metaplasia showed stronger positive reactions (Fig. 2-f). In addition, some cells with loss of polarity at the site of stromal differentiation displayed positive reaction in comparison with the weak reaction in solid tumor nests.

The cytoskeleton CK7 is positive in the cytoplasm of cuboidal cells forming duct-like structures in solid tumor nests. A similar immunofluorescent reaction in the cytoplasm of cuboidal tumor cells forming duct-like structures was noticed. CK13 was mainly positive in the cytoplasm of squamous epithelioid and basaloid cells in the area displaying squamous metaplasia but no reaction was observed in other sites. Positive reactions were mainly observed in the cytoplasm of basaloid and squamous epithelioid cells in tumor displaying squamous metaplasia.

With regard to Wnt 1 and $\beta$-catenin, Wnt showed strong positive reaction mainly in small cuboidal cells in the tumor nests with advanced growth. $\beta$-catenin was also positive in almost the same region. In addition, nuclear translocation of $\beta$-catenin was confirmed in cuboidal cells forming duct-like structures in particular. However, the positive reaction became weak in areas with squamous metaplasia. Localization in the nucleus of basaloid cells located at the margin of tumor nests was also evident. However, nuclear translocation was not observed in squamous epithelioid cells.

In the double staining of Wnt1 and CK7, Wnt showed strong positive reaction in the area with small cuboidal cells within the solid tumor nests. On the other hand, in the region with polygonal and spindle cells constituting the myxomatous part, a positive reaction was observed in some cells but compared to the site with solid tumor nests, Wnt1 reaction was stronger in the cytoplasm and nucleus of spindle-shaped cells (Fig. 3-a). In the cells that form duct-like structures, Wnt1 and CK7 were observed simultaneously (Fig. 3-b). The overlapping of the stains is clear (Fig. 3-c, d).

In the double staining of Wnt1 and CK13, Wnt was localized in the cytoplasm in a wide variety of cells forming tumor nests. Wnt showed strong positive reaction in tumor nests with advanced growth. A strong positive reaction was also observed in polygonal cells and in small cuboidal cells that formed aggregated solid nests. Moreover, cells that form duct-like structures in solid nests were also strongly positive (Fig. 4-a). However, CK13 was positive mainly in the cytoplasm of squamous epithelioid cells found in squamous metaplasia (Fig. 4-b). The overlapping of staining is clear (Fig. 4-c, d). 


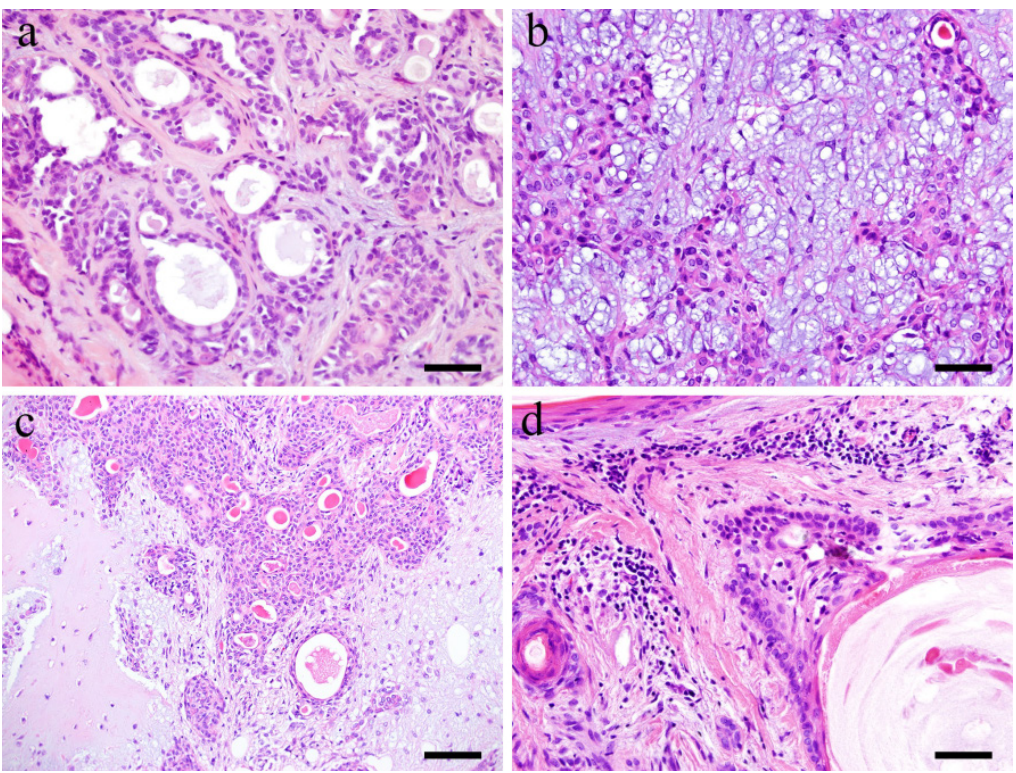

Figure I. Histopathological appearances. a: Duct-like structure in Case 5: 73-year-old male, palate, scale bar= 50 $\mu$ m; b: Neoplastic myoepithelial cells within the tissue in Case 8: 68-year-old female, palate, scale bar $=50 \mu \mathrm{m}$; c: Cartilaginous tissues in Case 12: 58 -year-old male, mandibular gland, scale bar= $100 \mu \mathrm{m}$; d: Squamous metaplastic tissues in Case 30: 40-year-old male, palate, scale bar $=50 \mu \mathrm{m}$.
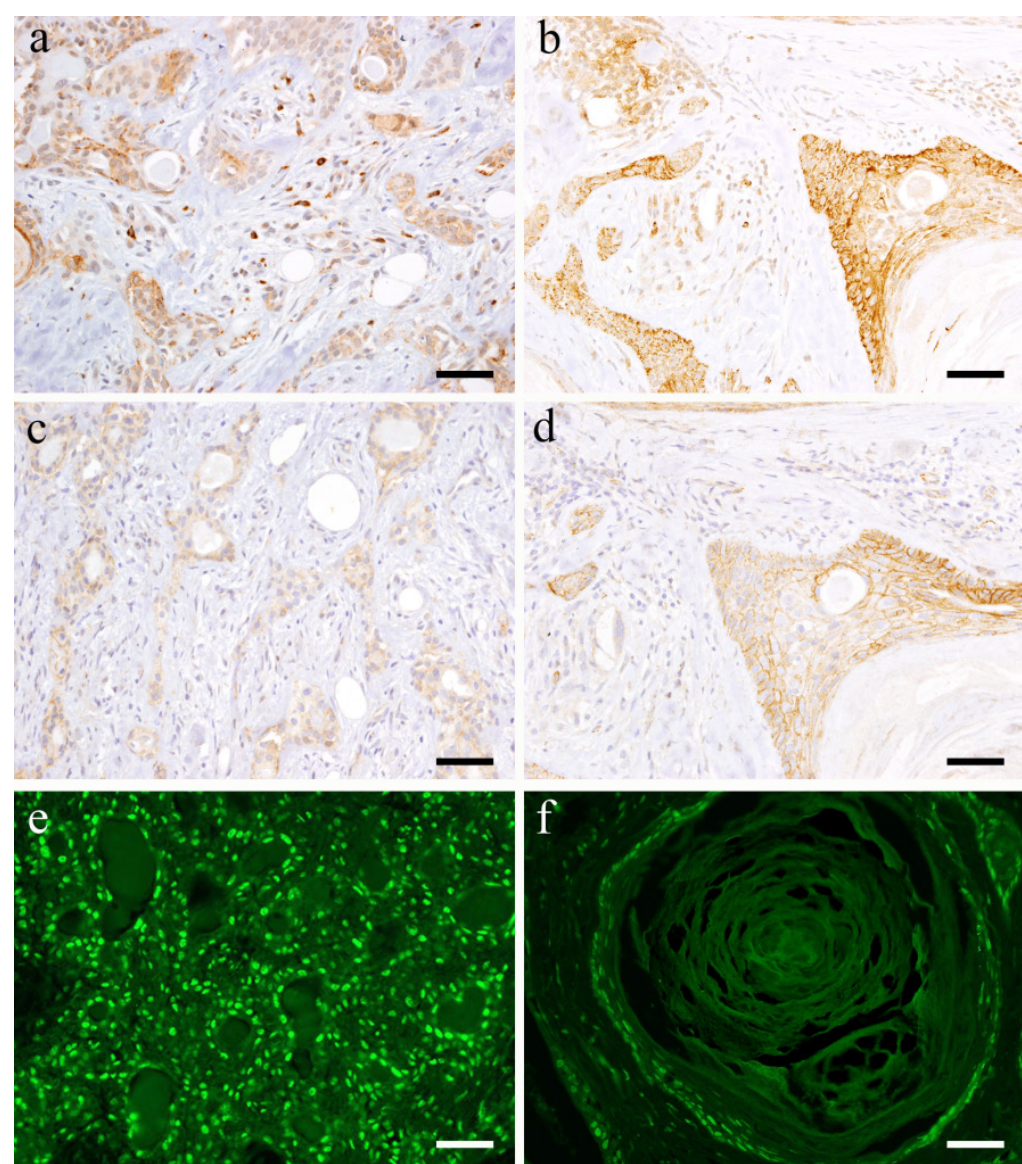

Figure 2. IHC and IF features. a: Wntl-positive staining in the solid tumor cell nests in Case 29: 62-year-old female, upper lip, Scale bar= 50 $\mu \mathrm{m}$; b: Wntl-postitive products shown in squamous metaplasia of Case 30: 40 -year-old male, palate, scale bar $=50 \mu \mathrm{m}$; c: $\beta$-catenin-positive staining shown in the tissue of Case 29: 62-year-old female, upper lip, Scale bar $=50 \mu \mathrm{m}$; d: $\beta$-catenin-positively observed in the duct-like structures in Case 30: 40-year-old male, palate, scale bar $=50 \mu \mathrm{m}$; e: IF of $\beta$-catenin shown in Case 29: 62-year-old female, upper lip, Scale bar $=50 \mu \mathrm{m}$; f: IF of $\beta$-catenin shown in Case 30: 40-year-old male, palate, scale bar $=50 \mu \mathrm{m}$. 

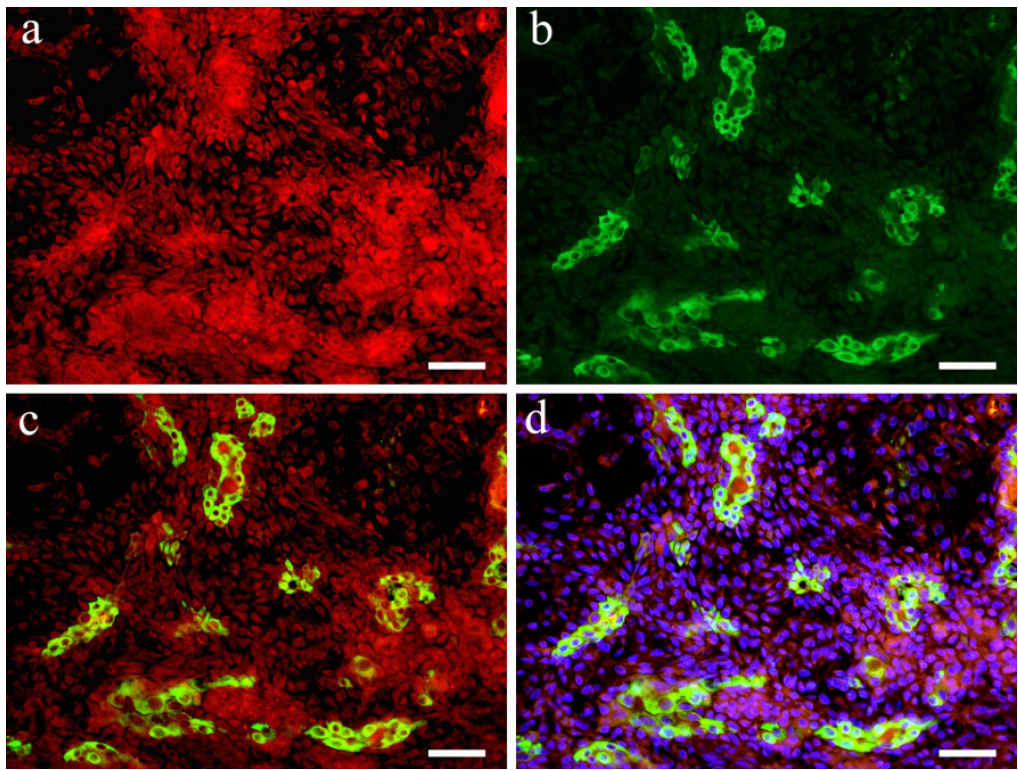

Figure 3. IF images. Wntl and CK7 positive staining shown in Case 29 (62-year-old female, upper lip, scale bar= 50 $\mu \mathrm{m})$. a: Wntl; b: CK7; c: Merge image of Wintl and CK8; d: Merge image of WntI, CK7 and DAPI.
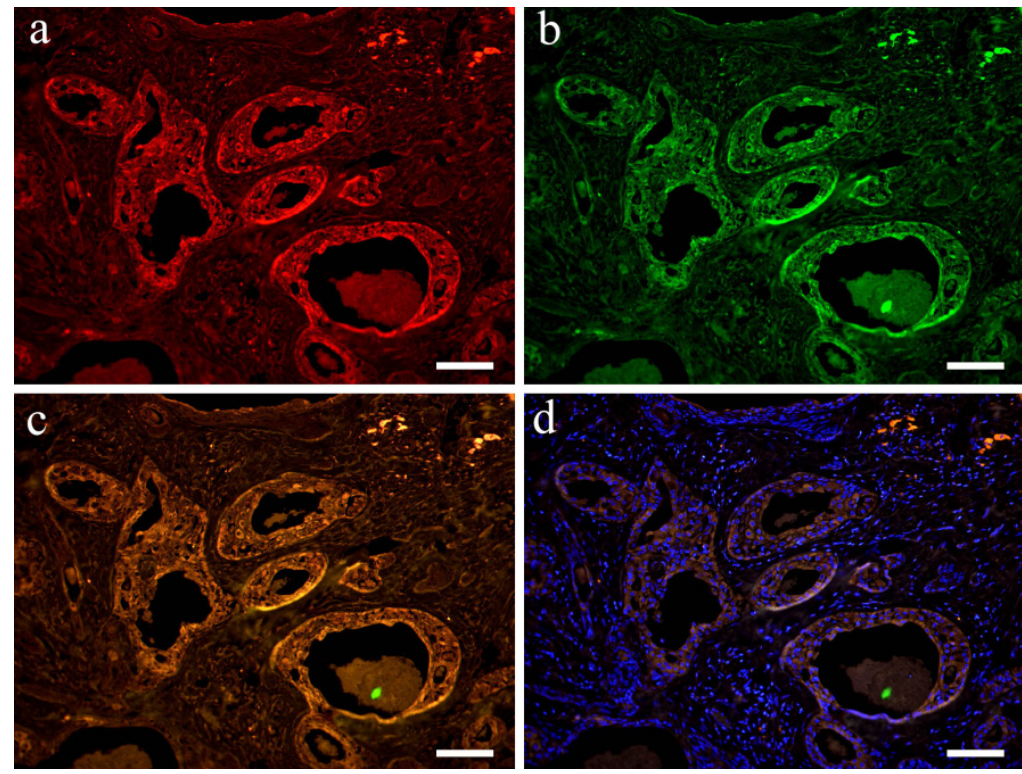

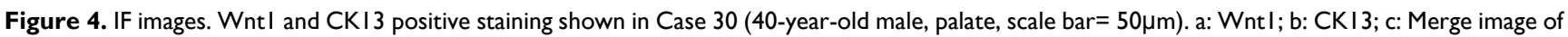
Wint I and CKI3; d: Merge image of WntI, CKI3 and DAPI.

\section{Discussion}

At first, there are no positive controls for this examination. The examination materials all are from clinically exited human surgical materials. Therefore, there are impossible to prepare the positive controls. According to the results, there were determined the specific localization of all examined results: Wnt1, $\beta$-catenin, CK7 and CK1. These results have thought to means true of this distribution pattern. Various researches regarding tumor development, cell differentiation and progression have been carried out producing clinical impact. In recent years, studies re- garding the expressions of various factors in tumor tissues responsible for cell differentiation have been pursued and many have been reported (5-9). In the oral cavity, studies in odontogenic tumors including ameloblastoma in particular have been carried out (10-12). Recently, Wnt signaling has been involved in calcifying cystic odontogenic tumor, odontoma, calcifying epithelioma and in ameloblastoma type craniopharyngoma. Consequently, the ghost cells showed strong positive reaction to antibodies against hair proteins. Moreover, Wnt signaling is believed to be responsible for the increase $\beta$-catenin expression in the cytoplasm and nucleus of epithelial cells in close 
proximity as well as the nuclear localization of Lef-1 (13).

Wnt is responsible for cell proliferation, differentiation and homeostasis although researches have also shown that Wnt is associated with suppression of cell proliferation and tissue differentiation (14). Wnt is an extracellular secretory protein that is variously expressed and widely conserved. Although regulation of gene expression, cell proliferation, cell motility, cell polarity and maintenance of homeostasis in regenerating organs are its inherent actions, when the signal is abnormal, the liquid-crystal molecules play important roles in pathological aspects such as malignant transformation and invasion in cancer as well as various physiological transitions (15). Under physiological conditions typical in $\beta$-catenin pathway, the protein accumulates in the cytoplasm and is translocated into the nucleus due to Wnt signaling. The protein later on combines with Tcf/Lef transcription factors and promotes the expression of genes such as Cyclin D1 and c-Myc $(16,17)$. $\beta$-catenin expression is held low if there is no stimulation of Wnt. Considering its relation to the differentiation of tumor cells, the advent of hard keratin expression in ghost cells in tumors has been reported in Wnt signaling pathway $(18,19)$.

In $\beta$-catenin pathway, cytoplasmic $\beta$-catenin protein adjusts its weight to suppress gene expression. In the absence of Wnt, $\beta$-catenin forms complex with Axin, tumor suppressor gene product APC, casein kinase $1 \mathrm{a}$ and glycogen synthase kinase-3b (GSK-3b). In CK1a and GSK-3b complex, $\beta$-catenin is degraded in the proteasome after being phosphorylated efficiently and then undergoes ubiquitination, keeping its amount low in the cytoplasm. However, Wnt binds to Frizzled and LRP 5/6 and then signals are transmitted into the cell to suppress phosphorylation of $\beta$-catenin. The state of low phosphorylation of $\beta$-catenin promotes the formation of complex of transcription factor T-cell/lymphoid enhancer factor and promotes the formation of Cyclin D1 and c-Myc proteins, to suppress the proliferation and differentiation of cells. On the other hand, two pathways have at least been identified in non- $\beta$-catenin pathway namely PCP and Ca2+ pathways (20). Suppression of $\beta$-catenin pathway is known in these pathways.

Furthermore in odontogenic tumors like ameloblastoma (21), calcifying cystic odontogenic tumor (22-25), odontoma and calcifying epithelioma, Wnt signaling through $\beta$-catenin pathway is involved in ghost cells (26). Although the functions of Wnt signaling in salivary gland tumors especially on malignant tumors have also been done in cell cultures, likewise, we thought that Wnt signaling is involved in malignant salivary gland tumors (27).
Currently, there are only few researches on cell differentiation in pleomorphic adenoma particularly in Wnt signaling. Therefore, in this experiment, we examined the localization of Wnt signaling as well as various factors involved in cell differentiation in pleomorphic adenoma. Due to the 'mixed' characteristic of pleomorphic adenoma, especially the formation of mesenchymal-like component, bone morphogenetic protein (BMP) factors in the formation of cartilaginous or distinct bone tissues have been implicated in studies. However, the cartilage-like cells in major salivary gland tumors strongly expressed type II collagen but cartilage-like cells in minor salivary gland tumors expressed type I collagen. In hyaline cartilaginous tissue of major salivary gland tumors, BMPs related to cartilage formation like BMP-2, BMP-4, BMP-6, fibroblast growth factor-2 and chondromodulin-1 are known to be strongly expressed. From the above, cartilaginous tissues can be easily formed more in major salivary gland tumors than in the minor salivary gland tumors and the involvement of neoplastic myoepithelial cells in the formation of cartilaginous tissue has been suggested (29). The type of collagen in cartilage tissue as well as the differentiation of cells in the cartilaginous tissue in pleomorphic adenoma formed in pleomorphic adenoma has been found to be almost similar to the normal hyaline cartilage (30).

Moreover, analysis of the cytokeratin focused on the biphasic cell differentiation of myoepithelial cell in pleomorphic adenoma has been conducted hence CK7 and CK13 were selected this time $(31,32)$. In the present study, the small cuboidal cells in solid tumor cell nests showed strong positive reaction to Wnt as well as to $\beta$-catenin with nuclear reaction recognized in the latter protein. This suggests that Wnt is working through the $\beta$-catenin pathway. In the study of neural stem cells, Wnt may require the activation of Notch signaling known to suppress cell differentiation. $\beta$-catenin binds to Hes1 gene in the promoter region due to the inhibitory effect of the cell (33).

CK7 was positive in cells that formed ductal structures. Wnt showed a strong positive reaction in the area where small cuboidal cells accumulated to form solid tumor cell nests. The site deeply positive to Wnt and CK7 is consistent with the expression of CK7 alone wherein numerous duct-like structures were formed (34). In the cells that form duct-like structures, strong expression of both Wnt and CK7 was confirmed. At the sites of $\beta$-catenin localization, nuclear migration was observed strongly in small cuboidal cells distributed outside the duct-like structures. In spindle-shaped cells at the periphery of duct-like structures, Wnt had similar staining with $\beta$-catenin. Thus, in tumor cells that form duct-like especially the 
small cuboidal cells, Wnt signaling works though $\beta$-catenin pathway while in the spindle-shaped cells arranged in cord-like structures, the expression of Wnt and $\beta$-catenin was not nearly recognized. Wnt expression in small cuboidal cells forming duct-like structures in solid nests was considered to be associated with cell differentiation.

In the area stained with CK13, the squamous epithelioid cells indicating the site of squamous metaplasia showed Wnt positive reaction. Furthermore, Wnt exhibited strong positive reaction in peripheral columnar cells of tumor nests in particular. However, positive reaction in cells with advanced differentiation was weak. Similarly, $\beta$-catenin showed positive reaction in squamous metaplasia. The deep staining around cell membrane was recognized in many cells but no cytoplasmic and nuclear translocation was detected. This trend was observed in basaloid cells especially around the tumor nest only in a small portion but there was also a site of nuclear translocation. It is suggested that Wnt is working through $\beta$-catenin pathway in squamous epithelioid cells that form tumor nests and partly in basaloid cells in surrounding nests (35). Although Wnt is expressed in many cells, nuclear translocation of $\beta$-catenin did not occur suggesting that a different pathway for Wnt signaling might have occurred. Moreover, in myxomatous and cartilaginous cells, Wnt and $\beta$-catenin expressions were weak and the expression is considered for the performance of Wnt function. The important findings are the almost overlapping of the IHC staining results and IF results. We considered that there are no meaning of the positive ratio of IHC and IF.

In summary, in pleomorphic adenoma, Wnt is involved in cell differentiation of tumor cells that form solid nests and cuboidal cells that form duct-like structures through $\beta$-catenin pathway (36). Moreover, it is suggested that Wnt is functioning through $\beta$-catenin pathway in tumor cells with advanced differentiation particularly the basaloid cells in squamous metaplasia. In the 'mixed' characteristic of pleomorphic adenoma, although Wnt through $\beta$-catenin pathway is greatly involved in cell differentiation, another pathway is considered responsible for the change in cell morphology. Thus, the examination results suggest that Wnt signaling act as a promoting factor of cell differentiation in pleomorphic adenomas, especially in the areas of squamous metaplastic differentiation in pleomorphic adenoma tissues.

\section{Acknowledgments}

This study was supported in part by a Grant-in-Aid for Scientific Research (C) (\# 23592951 and \#26463031) from the Japan Society for the Promotion of Science.

\section{Competing Interests}

The authors have declared that no competing interest exists.

\section{References}

1. Eveson JW, Kusafuka K, Stenman G and Nagao T. Pleomorphic adenoma. In: World Health Organization Classification of Tumours. In: Barnes L, Eveson JW, Reichart P and Sidransky D, eds. Pathology and Genetics of the Head and Neck Tumours. Lyon, France: IARC Press. 2005: 254-60.

2. Akiyama W. A Histopathological and immunohistochemical study of cartilage-like tissue formation in pleomorphic adenoma: Comparative study of the major and minor salivary gland adenomas. Int J Oral Med Sci 2012; 10: 384-99.

3. Nakano K, Takehiro W, Takako S and Toshiyuki K. Immunohistochemical characteristics of bone forming cell in pleomorphic adenoma. Int J Med Sci 2007; 4: 264-66.

4. Arend RC, Londoño-Joshi AI, Straughn JM Jr and Buchsbaum DJ. The Wnt/ $\beta$-catenin pathway in ovarian cancer: A review. Gynecol Oncol 2013; 131: 772-9.

5. Hao J, Zhang Y, Jing D, Li Y, Li J and Zhao Z. Role of Hippo signaling in cancer stem cells. J Cell Physiol 2014; 229: 266-70.

6. Zhao J, Wang S, Liu N and Tang X. Correlation between the expression of Id-1 and hyperthermia-associated molecules in oral squamous cell carcinoma. J Clin Pathol 2013; 66: 758-63.

7. Simons AL, Lu P, Gibson-Corley KN, Robinson RA, Meyerholz DK and Colgan JD. The Justy mutant mouse strain produces a spontaneous murine model of salivary gland cancer with myoepithelial and basal cell differentiation. Lab Invest 2013; 93: 711-9.

8. Khan Z and Bisen PS. Oncoapoptotic signaling and deregulated target genes in cancers. Biochim Biophys Acta 2013; 1836: 123-45.

9. Isobe T, Yamamoto G, Irie T, Tachikawa T and Mishima K. Gene expression of cancer stem cell in oral squamous cell carcinoma. Dent Med Res 2012; 32: 81-89.

10. Fujita M, Nakano K, Funato A, Sugita Y, Kubo K, Maeda H, Okafuji N, Hasegawa $\mathrm{H}$ and Kawakami T. Heat shock protein27 expression and cell differentiation in ameloblastomas. Int J Med Sci 2013; 10: 1271-7.

11. Siar $\mathrm{CH}$, Nakano $\mathrm{K}$, Han PP, Tomida $\mathrm{M}$, Tsujigiwa $\mathrm{H}$, Nagatsuka $\mathrm{H}, \mathrm{Ng} \mathrm{KH}$ and Kawakami T. Co-expression of BMP-2 and -7 in the tumoral epithelium of CEOT with selective BMP-7 Expression in amyloid materials. J Hard Tissue Biol 2011; 20: 125-132.

12. Kishino M, Murakami S, Yuki M, Iida S, Ogawa Y, Kogo M and Toyosawa S. A immunohistochemical study of the peripheral ameloblastoma. Oral Dis 2007; 13: $575-80$.

13. Siar $\mathrm{CH}$, Nagatsuka $\mathrm{H}$, Han PP, Berry RR, Tsuijigiwa $\mathrm{H}$, Nakano $\mathrm{K}, \mathrm{Ng} \mathrm{KH}$ and Kawakami T. Differential expression of canonial and non-canonial Wnt ligands in ameloblatoma. J Oral Pathol Med 2012; 41: 332-9.

14. Li PP and Wang X. Role of signaling pathways and miRNAs in chronic lymphocytic leukemia. Chin Med J 2013; 126: 4175-82.

15. Declercq J, Van Dyck F, Van Damme B and Van de Ven WJ. Upregulation of Igf and Wnt signalling associated genes in pleomorphic adenomas of the salivary glands in PLAG1 transgenic mice. Int J Oncol. 2008; 32: 1041-7.

16. Logan $\mathrm{CY}$ and Nusse R. The Wnt signaling pathway in development and disease. Annu Rev Cell Dev Biol 2004; 20: 781-810.

17. Kikuchi A, Yamamoto $\mathrm{H}$ and Kishida S. Multiplicity of the interactions of Wnt proteins and their receptors. Cell Signal 2007; 19: 659-71.

18. Kikuchi $\mathrm{A}$ and Yamamoto $\mathrm{H}$. Tumor formation due to abnormalities in the $\beta$-catenin-independent pathway of Wnt signaling. Cancer Sci 2008; 99: 202-8.

19. Miyoshi K, Rosner A, Nozawa M, Byrd C, Morgan F, Landesman-Bollag E, Xu X, Seldin DC, Schmidt EV, Taketo MM, Robinson GW, Cardiff RD and Hennighausen L. Activation of different Wnt/beta-catenin signaling components in mammary epithelium induces transdifferentiation and the formation of pilar tumors. Oncogene 2002; 21: 5548-56.

20. Veeman MT, Axelrod JD and Moon RT. A second canon. Functions and mechanisms of beta-catenin-independent Wnt signaling. Dev Cell 2003; 5: 367-77.

21. Chuah KS, Siar CH, Nakano K, Nagatsuka H, Khoo SP, Ng KH and Kawakami T. Wingless-type protein-1 (Wnt-1) expression in primary conventional and unicystic ameloblastomas and their recurrent tumors. J Hard Tissue Biol 2009; 18: 63-70.

22. Mehendiratta M, Bishen KA, Boaz K and Mathias Y. Ghost cells: A journey in the dark.... Dent Res J (Isfahan) 2012; 9 (Supple 1): S1-8.

23. Ahn SG, Kim SA, Kim SG, Lee SH, Kim J and Yoon JH. Beta-catenin gene alterations in a variety of so-called calcifying odontogenic cysts. APMIS 2008; 116: 206-11.

24. Kim SA, Ahn SG, Kim SG, Park JC, Lee SH, Kim J and Yoon JH. Investigation of the beta-catenin gene in a case of dentinogenic ghost cell tumor. Oral Surg Oral Med Oral Pathol Oral Radiol Endod 2007; 103: 97-101.

25. Hassanein AM, Glanz SM, Kessler HP, Eskin TA and Liu C. Beta-catenin is expressed aberrantly in tumors expressing shadow cells. Pilomatricoma, craniopharyngioma, and calcifying odontogenic cyst. Am J Clin Pathol. 2003; 120: $732-6$ 
26. Tanaka A, Okamoto M, Yoshizawa D, Ito S, Alva PG, Ide F and Kusama K. Presence of ghost cells and the Wnt signaling pathway in odontomas. J Oral Pathol Med 2007; 36: 400-4.

27. Queimado L, Obeso D, Hatfield MD, Yang Y, Thompson DM and Reis AM. Dysregulation of Wnt pathway components in human salivary gland tumors. Arch Otolaryngol Head Neck Surg 2008; 134: 94-101.

28. Wend P, Fang L, Zhu O, Schipper JH, Loddenkemper C, Kosel F, Brinkmann V, Eckert K, Hindersin S, Holland JD, Lehr S, Kahn M, Ziebold U and Birchmeier W. Wnt/ $\beta$-catenin signalling induces MLL to create epigenetic changes in salivary gland tumours. EMBO J $2013 ; 32: 1977-89$.

29. Kusafuka K, Luyten FP, D Bondt R, Hiraki Y, Shukunami C, Kayano T and Takemura T. Immunohistochemical evaluation of cartilage-derived bone morphogenic protein-1 and -2 in normal human salivary glands and pleomorphic adenomas. Virchows Arch 2003; 442: 482-90.

30. Kusafuka K, Yamaguchi A, Kayano T and Takemura T. Immunohistochemical localization of the bone morphogenetic protein-6 in salivary pleomorphic adenomas. Pathol Int 1999; 49: 1023-7.

31. Fonseca FP, de Andrade BA, Rangel AL, Della Coletta R, Lopes MA, de Almeida OP and Vargas PA. Tissue microarray is a reliable method for immunohistochemical analysis of pleomorphic adenoma. Oral Surg Oral Med Oral Pathol Oral Radiol 2014; 117: 81-8.

32. Araújo VC, de Sousa SO, Carvalho YR and Araújo NS. Application of immunohistochemistry to the diagnosis of salivary gland tumors. Appl Immunohistochem Mol Morphol 2000; 8: 195-202.

33. Koziński $\mathrm{K}$ and Dobrzyń A. Wnt signaling pathway - its role in regulation of cell metabolism. Postepy Hig Med Dosw 2013; 67: 1098-108.

34. Keck B, Stoehr R, Wach S, Rogler A, Hofstaedter F, Lehmann J, Montironi R, Sibonye M, Fritsche HM, Lopez-Beltran A, Epstein JI, Wullich B and Hartmann A. The plasmacytoid carcinoma of the bladder--rare variant of aggressive urothelial carcinoma. Int J Cancer 2011; 129: 346-54.

35. Kikuchi A. Roles of Axin in the Wnt signalling pathway. Cell Signal 1999; 11: 777-88.

36. Saito T, Mitomi H, Imamhasan A, Hayashi T, Mitani K, Takahashi M, Kajiyama $Y$ and $Y$ ao T. Downregulation of sFRP-2 by epigenetic silencing activates the $\beta$-catenin/ Wnt signaling pathway in esophageal basaloid squamous cell carcinoma. Virchows Arch $2014 ; \% 26$ 